\title{
Stratification Using hTERT and Stem Cell Markers Confers a Good Prognosis in Invasive Breast Cancer
}

\author{
UMAR WAZIR $^{1,2}$, SALIM TAYEH $^{1}$, MONA A.W. ORAKZAI $^{1}$, \\ TRACEY A. MARTIN ${ }^{3}$, WEN G. JIANG ${ }^{3}$ and KEFAH MOKBEL ${ }^{1,2}$ \\ ${ }^{1}$ The London Breast Institute, Princess Grace Hospital, London, U.K.; \\ ${ }^{2}$ Department of General Surgery, Khyber Teaching Hospital, Peshawar, Pakistan; \\ ${ }^{3}$ Cardiff-China Cancer Research Collaboration, \\ Cardiff University School of Medicine, Cardiff University, Cardiff, U.K.
}

\begin{abstract}
Background/Aim: In this study, we aimed to investigate the prognostic role of a previously identified panel of 10 stem cell markers stratified against the catalytic subunit of telomerase (hTERT) in human breast cancer. Materials and Methods: The mRNA copy numbers of these genes were determined using real time quantitative PCR in 124 breast cancer tissues and adjacent non-cancerous tissues. Relations between mRNA levels and survival were analysed using Kaplan-Meier plots and Cox regression analysis. Results: Five genes (BMI1, NES, POU5F1, ALDHIA2 and CDKN1A) correlated with survival when stratified with hTERT and predicted overall (Wilcoxon: $p=0.004$; Cox: $p=0.006$ ) and disease-free (Wilcoxon: $p<0.000$; Cox: $p=0.000$ ) survival. Conclusion: This panel of genes stratified by hTERT could open new avenues for the development of new prognostic tools, as well as for the identification of new research directions regarding breast oncogenesis.
\end{abstract}

Breast cancer remains the commonest cancer among women and the second most common cause of cancer-related female mortality in the UK, accounting for $15 \%$ of all cancer-related death in women in 2016 (1). This is despite improvements in survival due to refinements in therapy and better understanding of the underlying pathology over the last several decades (2). A major step forward in understanding breast cancer has been the recognition of the disease as a diverse collection of molecular entities distinguished by specific genomic signatures. This has been the basis of the currently evolving

This article is freely accessible online.

Correspondence to: Professor Kefah Mokbel, London Breast Institute, the Princess Grace Hospital, 45 Nottingham Place, London W1U 5NY, U.K. E-mail: kefahmokbel@hotmail.com

Key Words: Prognosis, pluripotency, breast cancer, cell cycle. genomic assays which have revolutionised decision-making in breast cancer treatment, and have highlighted the need for personalised cancer therapy $(3,4)$.

The study of stem cell markers in oncogenesis has been the focus of research in recent decades. The emergence of pluripotentiality is of interest in view of the high mitotic turnover in neoplasia. In addition, understanding of "stem-ness" has been especially important in the debate surrounding clonal proliferation within tumours, which has potential implications for therapeutic targeting and decision making regarding tumour resection in advanced disease $(5,6)$.

Recently, we have studied the relations between a panel of stem cell markers and human telomerase reverse transcriptase (hTERT) in the context of breast cancer (7). hTERT has an important role in cell immortality and senescence, and has been demonstrated to have a role in oncogenesis (8). Our study identified a subset of stem cell markers which have significant associations with hTERT in human breast cancer (7). These markers were B lymphoma Mo-MLV insertion region 1 homolog (mouse) (BMI1), nestin (NES), POU class 5 homeobox 1 (POU5F1), aldehyde dehydrogenase 1 family member A2 (ALDH1A2) and cyclin dependent kinase inhibitor $1 \mathrm{~A}$ (CDKN1A).

In the current study, we aimed to examine the role of hTERT and the 5 stem cell makers identified above in human breast cancer by analysing the association of their mRNA expression with clinical outcomes and survival in breast cancer (7).

\section{Materials and Methods}

Tissues samples. Tissue samples (124 cancer tissues and 30 healthy breast tissues) were obtained according to the local institutional guidelines and stored at $-80^{\circ} \mathrm{C}$ until mRNA analysis (8-10).

All the patients underwent breast cancer surgery and received adjuvant therapy according to local guidelines after multidisciplinary discussions. The clinical and pathological data (Table I) were collected from the patient charts, and were collated in an encrypted database $(5,11)$. 
RNA extraction and cDNA synthesis. The stem cell markers that were found to be significantly correlated with hTERT in our previous study were selected for the current project. These were: cluster of differentiation 24 (CD24), cluster of differentiation 29 (CD29, also known as integrin subunit beta 1; ITGB1), cluster of differentiation 44 (CD44), integrin subunit alpha 6 (ITGA6; also known as CD49F), BMI1, NES (previously known as neuroectodermal stem cell marker), POU5F1 (also known as OCT4), ALDH1A2, MET proto-oncogene (MET, also known as hepatocyte growth factor receptor), CDKN1A (also known as p21), and noggin (NOG). They are enumerated in Table II (7).

Approximately $10 \mathrm{mg}$ of tissue were used for quantitative RNA extraction and cDNA synthesis using the relevant kits obtained from AbGene Limited in the UK according to the instructions of the manufacturer $(5,11)$.

Quantitative RT-PCR. The cDNA transcripts were determined using real-time qPCR (Amplifluor technology). The PCR primers were designed using Beacon Designer software (Premier Biosoft International Ltd., Palo Alto, CA, USA), and were synthesized by Invitrogen Ltd. (Paisley, UK). The primers incorporated an additional sequence, known as the $\mathrm{Z}$ sequence (5'-ACTGAACCTGACCGTACA$3^{\prime}$ ), which is complementary to the universal $\mathrm{Z}$ probe (Intergen Inc., Oxford, UK).

The PCR reaction was carried out as follows: One cycle at $94^{\circ} \mathrm{C}$ for $15 \mathrm{~s}, 20$ cycles at $55^{\circ} \mathrm{C}$ for $40 \mathrm{~s}$, and one cycle at $72^{\circ} \mathrm{C}$ for $20 \mathrm{~s}$. The mRNA expression levels were normalised against cytokeratin 19 (CK19), a house-keeping gene. With every PCR cycle, a negative (PCR water) and positive control was employed, using a known cDNA sequence (podoplanin) $(5,11)$. Although all 124 samples were analysed, some samples had to be excluded due to spurious results caused by technical issues.

Statistical analysis. Correlations of stem cell panel molecules and clinicopathological parameters were performed using the SigmaPlot 11 statistical software package (Systat Software Inc). Survival analyses were conducted using Kaplan-Meier plots and Cox regression, and were performed using SPSS version 25 (IBM Corp, Armonk, NY, USA).

\section{Results}

The mRNA levels of the ten genes previously identified to be correlated with hTERT in the context of breast cancer were studied in relation to disease-free and overall survival. This was carried out using Kaplan-Meier plots plotted across a decade of follow-up. The cut off is the median value of expression in the cohort. The mRNA levels of BMI1, NES, POU5F1, ALDH1A2 and $C D K N 1 A$ were found to correlate independently with both overall and disease-free survival (Figure 1A and B), whilst those of ITGA6, MET, NOG, CD24 \& ITGB1 did not and were excluded from further analysis (Table II).

We discovered that when the mRNA expressions of these 5 genes were stratified using hTERT to divide the cohort, they predicted significant differences in both overall (Wilcoxon: $p=0.004$; Cox: $p=0.006$ ) and disease-free (Wilcoxon: $p<0.000$; Cox: $p=0.000$ ) survival (Figure 1C and D; Tables III and IV). Cox regression analysis showed that
Table I. Description of the clinical cohort.

\begin{tabular}{|c|c|}
\hline Parameter & $\begin{array}{c}\text { Number of } \\
\text { samples }\end{array}$ \\
\hline \multicolumn{2}{|l|}{ Tissue type } \\
\hline Background, normal & 30 \\
\hline Tumour & 124 \\
\hline \multicolumn{2}{|l|}{ Tumour grade } \\
\hline 1 & 24 \\
\hline 2 & 42 \\
\hline 3 & 58 \\
\hline \multicolumn{2}{|l|}{ Nottingham prognostic index } \\
\hline Grade 1 & 68 \\
\hline Grade 2 & 38 \\
\hline Grade 3 & 16 \\
\hline Unknown & 2 \\
\hline \multicolumn{2}{|l|}{ TNM Stage } \\
\hline 1 & 70 \\
\hline 2 & 40 \\
\hline 3 & 7 \\
\hline 4 & 4 \\
\hline Unknown & 3 \\
\hline \multicolumn{2}{|l|}{ Histology } \\
\hline Ductal & 94 \\
\hline Lobular & 14 \\
\hline Other & 16 \\
\hline \multicolumn{2}{|l|}{ Patient outcome } \\
\hline Alive and well & 85 \\
\hline Metastatic disease & 7 \\
\hline Death from breast cancer & 15 \\
\hline $\begin{array}{l}\text { All poor outcomes } \\
\text { (Metastatic disease \& disease-related mortality) }\end{array}$ & 27 \\
\hline
\end{tabular}

TNM: Tumour, node and metastases staging (12).

stratified mRNA expression of the aforementioned 5 molecules correlated with overall $(p=0.003)$ and disease-free survival $(p=0.007)$ within the cohort.

\section{Discussion}

The predominant opinion regarding cell proliferation within solid tumours has been that they consist of a body of dividing neoplastic cells which give rise to new clonal lineages marked with changes in aspects of cellular behaviour, such as migration, invasion and proliferation, as well as other genetic changes which contribute to post-treatment relapses and the emergence of therapeutic resistance (12).

More recently, there has been evidence suggesting a hierarchy amongst tumour lineages with some cell lines within the tumour behaving as stem cells, playing a central role in the proliferation and evolution of the disease. This has been termed the cancer stem-cell hypothesis, and was initially described by Bonnet \& Dick in 1997 (13). This model has focussed interest in the role of stem cell markers, and cancer stem cells (CSC) in oncogenesis. CSCs have been 
Table II. Correlations of mRNA expression (normalised to CK19) of stem cell markers with that of TERT by Spearman rank correlation test.

\begin{tabular}{|c|c|c|c|c|}
\hline Gene symbol & Molecule encoded & $\begin{array}{l}\text { Correlation } \\
\text { coefficient (R) }\end{array}$ & $p$-Value & $\begin{array}{c}\text { Number of } \\
\text { samples }\end{array}$ \\
\hline$C D 24$ & $\begin{array}{c}\text { Cluster of differentiation } 24 \text { (CD24), also known as small } \\
\text { cell lung carcinoma cluster } 4 \text { antigen }\end{array}$ & 0.269 & 0.0114 & 88 \\
\hline ITGB1 & integrin subunit beta 1 , also known as CD29 & 0.476 & $<0.001$ & 88 \\
\hline ITGA6 & integrin subunit alpha 6 . Also known as $C D 49 F$ & 0.663 & $<0.001$ & 88 \\
\hline BMII & $\begin{array}{l}B M I 1 \text { proto-oncogene or polycomb ring finger } 4 . \\
\text { Previously known as B lymphoma Mo-MLV insertion } \\
\text { region } 1 \text { homolog (mouse) (BMI1) }\end{array}$ & 0.581 & $<0.001$ & 88 \\
\hline$N E S$ & Nestin. Previously known as neuroectodermal stem cell marker & 0.581 & $<0.001$ & 88 \\
\hline POU5F1 & $\begin{array}{l}\text { POU domain, class } 5 \text {, transcription factor } 1 \text {, also known as } \\
\text { OCT4: (octamer-binding transcription factor } 4 \text { ) }\end{array}$ & 0.651 & $<0.001$ & 88 \\
\hline$A L D H 1 A 2$ & Aldehyde dehydrogenase 1 family member A2 & 0.233 & 0.0298 & 87 \\
\hline MET & MET proto-oncogene. Also known as hepatocyte growth factor receptor & 0.591 & $<0.001$ & 76 \\
\hline CDKN1A & $\begin{array}{l}\text { Cyclin dependent kinase inhibitor 1A, also known } \\
\text { as p21: (protein of } 21 \mathrm{kDa} \text { atomic weight) }\end{array}$ & 0.611 & $<0.001$ & 88 \\
\hline$N O G$ & Noggin & 0.421 & $<0.001$ & 93 \\
\hline
\end{tabular}

Table III. Cox regression model for disease-free survival.

\begin{tabular}{lrrrrrr}
\hline & \multicolumn{5}{c}{ Variables in the equation } \\
\cline { 2 - 5 } & Beta & Standard error & Wald test & df & Significance $(p)$ Hazard ratio \\
\hline Exp(B) & & & & & & \\
Nottingham Prognostic Index & 0.789 & 0.354 & 4.978 & 1 & 0.026 & 2.202 \\
Tumour grade & 0.295 & 0.260 & 1.284 & 1 & 0.257 & 1.343 \\
TNM stage & 0.473 & 0.181 & 6.810 & 1 & 0.009 & 1.604 \\
High mRNA expression of 5-gene panel stratified by TERT & -0.341 & 0.114 & 8.928 & 1 & 0.003 & 0.711 \\
\hline
\end{tabular}

Table IV. Cox regression model for overall survival.

\begin{tabular}{lrrrrrr}
\hline & \multicolumn{5}{c}{ Variables in the equation } \\
\cline { 2 - 5 } & Beta & Standard error & Wald test & df & Significance $(p)$ Hazard ratio \\
\hline Exp(B) & & & & & & \\
Nottingham Prognostic Index & 0.884 & 0.339 & 6.806 & 1 & 0.009 & 2.420 \\
Tumour grade & 0.208 & 0.313 & 0.440 & 1 & 0.507 & 1.231 \\
TNM stage & 0.212 & 0.248 & 0.733 & 1 & 0.392 & 1.237 \\
High mRNA expression of 5-gene panel stratified by TERT & -0.248 & 0.092 & 7.363 & 1 & 0.007 & 0.780 \\
\hline
\end{tabular}

identified in melanomas (14), neoplasia of the brain (15), lung (16), prostate (17) and colon (18) cancers.

A major clinical implication of the cancer stem-cell hypothesis is pertaining therapeutic resistance. Conventional adjuvant therapy has been largely effective in the treatment of de novo disease. However, such non-specific treatments could select cancer cells which are resistant to therapy. This is believed to be the aetiology of therapeutic resistance and relapse of disease after adjuvant therapy (19).

However, if it is possible to achieve remissions by targeting a smaller subset of pluripotent cancer cells, this could potentially reduce the risk of relapse and therapeutic resistance, and may provide a discrete therapeutic target whose obliteration could potentially reverse the pathology (20). 

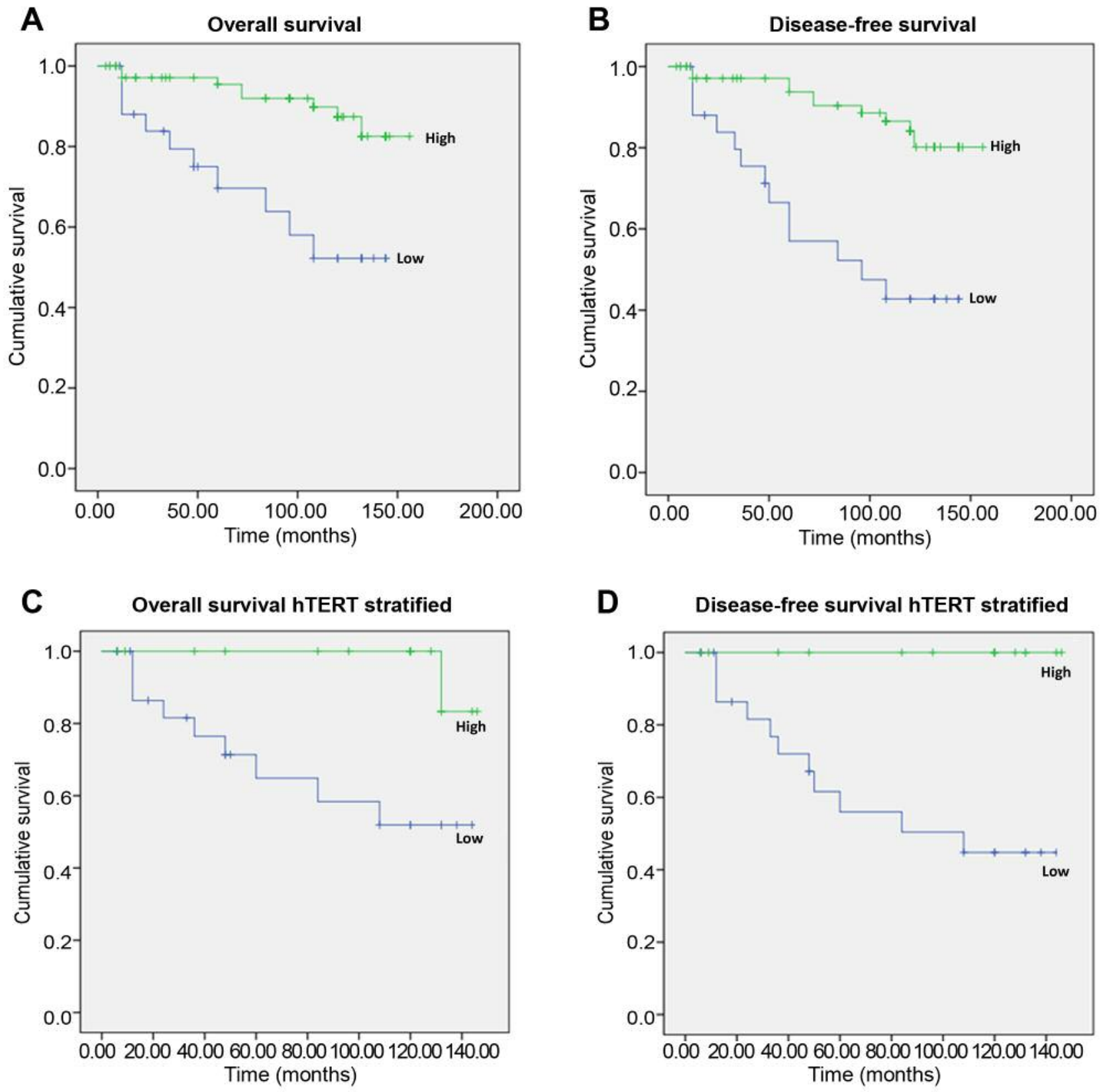

Figure 1. Survival curves using the 5 markers, BMI1, NES, POU5F1, ALDH1A2 and CDKN1A, to ascertain patient survival. A. Kaplan-Meier plot between high and low expression groups showing overall survival. The cut off is the median value of expression in the cohort. B. Kaplan-Meier plot between high and low expression groups showing disease-free survival. The cut off is the median value of expression in the cohort. C. KaplanMeier plot between high and low expression groups showing overall survival after stratification with hTERT. The cut off is the median value of expression in the cohort. D. Kaplan-Meier plot between high and low expression groups showing disease-free survival after stratification with hTERT. The cut off is the median value of expression in the cohort.

This has been the raison d'etre for much of the research into the role of stem cell markers in carcinogenesis. Whilst there have been some issues regarding reproducibility of results, as well as concerns regarding the suitability of the techniques and materials used (19), significant evidence has been accumulated regarding the role of known stem cell markers in human oncogenesis. For instance, the mRNA expression levels of stem cell markers, such as CD44 and ALDH1, have been found to be predictive of poor prognosis in breast carcinoma, suggesting that the so-called "stem-ness" is likely to have a role in solid tumours $(21,22)$. 
In our previous study, we studied the mRNA expression of hTERT, a regulator of cell aging, and that of a panel of 30 known stem cell markers in breast cancer tissue samples from a cohort of 124 patients (7). Previous studies had already established hTERT as a marker of poor prognosis in human breast cancer (8). Of the markers studied, we found 10 which directly correlated with hTERT. In our current project, we used this subset as a starting point for studying the relation of stem cell markers with clinical outcomes. We identified five that had significant implications as prognostic markers for poor clinical outcomes. Whilst we have to acknowledge the limitations of our study in terms of the paucity of protein expression data in our cohort, as well as the limited number of specimens, we anticipate that this would help direct future in vitro studies into the role of stem cell markers in human breast cancer. Specifically, genetic modification of the expression of the target molecules could yield important information regarding their effects on cell behaviour, such as invasion, proliferation and migration as well insights into the cellular mechanisms affected.

\section{Conclusion}

Our current study identified 5 stem cell markers that once stratified using hTERT are significantly related to clinical outcome in human breast cancer. Our findings will help future in vitro and mechanistic studies on the role of stem cells in human breast cancers, which hopefully would provide us with a better understanding of the micro-environment within human breast cancer and development of new therapeutic modalities.

\section{Conflicts of Interest}

The Authors have no conflicts of interest to report.

\section{Authors' Contributions}

The study was initiated and designed by KM and WGJ. TAM \& WGJ conducted the qPCR assays. WGJ curated the database and performed the data analysis. UW \& MWO performed the literature review and drafted the manuscript. KM \& MWO proof-read the manuscript.

\section{Acknowledgements}

This study was funded by grants from the Breast Cancer Hope Foundation (London, UK).

\section{References}

1 Cancer mortality for common cancers London, UK: Cancer Research UK; 2018. Available at: https://www.cancer researchuk.org/health-professional/cancer-statistics/mortality/ common-cancers-compared]

2 Narod SA, Iqbal J and Miller AB: Why have breast cancer mortality rates declined? J Cancer Policy 5: 8-17, 2015. DOI: $10.1016 /$ j.jcpo.2015.03.002
3 Wazir U, Mokbel K, Carmichael A and Mokbel K: Are online prediction tools a valid alternative to genomic profiling in the context of systemic treatment of ER-positive breast cancer? Cell Mol Biol Lett 22: 20, 2017. PMID: 28878809. DOI: 10.1186/ s11658-017-0049-x

4 Tang G, Shak S, Paik S, Anderson SJ, Costantino JP, Geyer CE, Jr., Mamounas EP, Wickerham DL and Wolmark N: Comparison of the prognostic and predictive utilities of the 21-gene Recurrence Score assay and Adjuvant! for women with nodenegative, ER-positive breast cancer: results from NSABP B-14 and NSABP B-20. Breast Cancer Res Treat 127(1): 133-142, 2011. PMID: 21221771. DOI: 10.1007/s10549-010-1331-z

5 Martin TA and Jiang WG: Evaluation of the expression of stem cell markers in human breast cancer reveals a correlation with clinical progression and metastatic disease in ductal carcinoma. Oncol Rep 31(1): 262-272, 2014. PMID: 24173498. DOI: 10.3892/or.2013.2813

6 Headon H, Wazir U, Kasem A and Mokbel K: Surgical treatment of the primary tumour improves the overall survival in patients with metastatic breast cancer: A systematic review and metaanalysis. Mol Clin Oncol 4(5): 863-867, 2016. PMID: 27123297. DOI: $10.3892 / \mathrm{mco} .2016 .778$

7 Wazir U, Orakzai MMAW, Martin TA, Jiang WG and Mokbel $\mathrm{K}$ : Correlation of TERT and stem cell markers in the context of human breast cancer. Cancer Genomics Proteomics 16(2): 121127, 2019. PMID: 30850363. DOI: $10.21873 / \mathrm{cgp} .20117$

8 Elkak A, Mokbel R, Wilson C, Jiang WG, Newbold RF and Mokbel K: hTERT mRNA expression is associated with a poor clinical outcome in human breast cancer. Anticancer Res 26(6C): 4901-4904, 2006. PMID: 17214359.

9 Al Sarakbi W, Sasi W, Jiang WG, Roberts T, Newbold RF and Mokbel K: The mRNA expression of SETD2 in human breast cancer: correlation with clinico-pathological parameters. BMC Cancer 9: 290, 2009. PMID: 19698110. DOI: 10.1186/14712407-9-290

10 Wazir U, Jiang WG, Sharma AK and Mokbel K: The mRNA expression of DAP3 in human breast cancer: correlation with clinicopathological parameters. Anticancer Res 32(2): 671-674, 2012. PMID: 22287761.

11 Jiang WG, Watkins G, Lane J, Cunnick GH, Douglas-Jones A, Mokbel K and Mansel RE: Prognostic value of rho GTPases and rho guanine nucleotide dissociation inhibitors in human breast cancers. Clin Cancer Res 9(17): 6432-6440, 2003. PMID: 14695145.

12 Nowell PC: The clonal evolution of tumor cell populations. Science 194(4260): 23-28, 1976. PMID: 959840.

13 Bonnet D and Dick JE: Human acute myeloid leukemia is organized as a hierarchy that originates from a primitive hematopoietic cell. Nat Med 3(7): 730-737, 1997. PMID: 9212098.

14 Fang D, Nguyen TK, Leishear K, Finko R, Kulp AN, Hotz S, Van Belle PA, Xu X, Elder DE and Herlyn M: A tumorigenic subpopulation with stem cell properties in melanomas. Cancer Res 65(20): 9328-9337, 2005. PMID: 16230395. DOI: 10.1158/0008-5472.CAN-05-1343

15 Singh SK, Clarke ID, Terasaki M, Bonn VE, Hawkins C, Squire $\mathrm{J}$ and Dirks PB: Identification of a cancer stem cell in human brain tumors. Cancer Res 63(18): 5821-5828, 2003. PMID: 14522905.

16 Kim CF, Jackson EL, Woolfenden AE, Lawrence S, Babar I, Vogel S, Crowley D, Bronson RT and Jacks T: Identification of 
bronchioalveolar stem cells in normal lung and lung cancer. Cell 121(6): 823-835, 2005. PMID: 15960971. DOI: 10.1016/j.cell. 2005.03.032

17 Patrawala L, Calhoun T, Schneider-Broussard R, Li H, Bhatia B, Tang S, Reilly JG, Chandra D, Zhou J, Claypool K, Coghlan L and Tang DG: Highly purified CD44+ prostate cancer cells from xenograft human tumors are enriched in tumorigenic and metastatic progenitor cells. Oncogene 25(12): 1696-1708, 2006. PMID: 16449977. DOI: 10.1038/sj.onc.1209327

18 Ricci-Vitiani L, Lombardi DG, Pilozzi E, Biffoni M, Todaro M, Peschle C and De Maria R: Identification and expansion of human colon-cancer-initiating cells. Nature 445(7123): 111-115, 2007. PMID: 17122771. DOI: $10.1038 /$ nature05384

19 Campbell LL and Polyak K: Breast tumor heterogeneity: cancer stem cells or clonal evolution? Cell Cycle 6(19): 2332-2338, 2007. PMID: 17786053. DOI: 10.4161/cc.6.19.4914

20 Dick JE: Breast cancer stem cells revealed. Proc Natl Acad Sci USA 100(7): 3547-3549, 2003. PMID: 12657737. DOI: 10.1073/pnas.0830967100
21 Ahmed MA, Aleskandarany MA, Rakha EA, Moustafa RZ, Benhasouna A, Nolan C, Green AR, Ilyas M and Ellis IO: A CD44(-)/CD24(+) phenotype is a poor prognostic marker in early invasive breast cancer. Breast Cancer Res Treat 133(3): 979-995, 2012. PMID: 22119938. DOI: 10.1007/s10549-0111865-8

22 Ginestier C, Hur MH, Charafe-Jauffret E, Monville F, Dutcher J, Brown M, Jacquemier J, Viens P, Kleer CG, Liu S, Schott A, Hayes D, Birnbaum D, Wicha MS and Dontu G: ALDH1 is a marker of normal and malignant human mammary stem cells and a predictor of poor clinical outcome. Cell Stem Cell 1(5): 555567, 2007. PMID: 18371393. DOI: 10.1016/j.stem.2007.08.014

Received November 28, 2019

Revised January 21, 2020

Accepted January 22, 2020 